\title{
PERANCANGAN SISTEM PENDATAAN IMUNISASI PADA POSYANDU WIJAYA KUSUMA
}

\author{
Dina Damayanti ${ }^{1}$, Dwi Yulistyanti ${ }^{2}$, Surajiyo $^{3}$ \\ ${ }^{1,2,3}$ Teknik Informatika, Fakultas Teknik dan Ilmu Komputer, Universitas Indraprasta PGRI \\ Jalan Raya Tengah No 80, Kelurahan Gedong, Pasar Rebo, Jakarta Timur \\ 12.
}

\begin{abstract}
ABSTRAK
Perkembangan komputer sangatlah pesat, hampir setiap tahun komputer selalu mengalami perkembangan, maka dari itu dukungan media computer sangatlah dibutuhkan khususnya dipelayanan masyarakat yang kita kenal sebagai Posyandu. Mengingat permasalahan yang dirasakan Posyandu Wijaya Kusuma ialah dalam pendataan dan pencatatan masih menggunakan kertas secara manual, hal ini tentu tidak efesien karena banyaknya data yang harus dicatat setiap bulannya dan jumlah anak serta hasil pemeriksaan berbeda, bisa bertambah ataupun berkurang. Tujuan penelitian ini guna mengenali system informasi pencatatan dan pengelohan data yang sedang berjalan di Posyandu Wijaya Kusuma , supaya bisa membangun aplikasi yang ada fitur pencatatan dan pengolahan data guna memudahkan user dalam menggunakannya. Dalam melakukan penelitian ini peneliti menggunakan penelitian Metode Research and Development dan metode kualitatif dan deskriptif serta Paradigma Siklus Hidup Klasik “Model Air Terjun”. Aplikasi pendataan imunisasi ini tercipta dengan dukungan bahasa pemrograman Java, Netbeans 8.2, XAMPP, serta database MySQL.
\end{abstract}

Kata Kunci : Sistem Pendataan, Imunisasi Posyandu, Java.

\begin{abstract}
The development of computers is very rapid, almost every year computers always experience development, therefore computer media support is needed, especially in community services which we know as Posyandu. Considering the problem felt by Posyandu Wijaya Kusuma is that data collection and recording still use paper manually, this is certainly not efficient because of the large amount of data that must be recorded every month and the number of children and the results of different examinations, can increase or decrease. The purpose of this study is to identify the data recording and processing information system that is currently running at the Wijaya Kusuma Posyandu, in order to be able to build applications that have data recording and processing features to make it easier for users to use them. In conducting this research, the researcher used Research and Development Methods and qualitative and descriptive methods as well as the Classical Life Cycle Paradigm "Waterfall Model". This immunization data collection application was created with the support of the Java programming language, Netbeans 8.2, XAMPP, and the MySQL database.
\end{abstract}

Key Word: Data Collection System, Immunization Posyandu,Java.

\section{PENDAHULUAN}

Pos pelayanan terpadu (Posyandu) merupakan salah satu wujud upaya kesehatan bersumberdaya warga yang dilaksanakan oleh, dari dan bersama warga, buat memberdayakan dan membagikan kemudahan kemudahan kepada warga guna mendapatkan perlayanan untuk bunda, balita dan anak bayi (Kemenkes RI, 2012). Di dalam posyandu ada sebagian aktivitas semacam kesehatan bunda dan anak, imunisasi, gizi dan sosialisasi kesehatan. Dalam aktivitas tersebut dibutuhkan Sistem Data Posyandu ( SIP) yang meliputi catatan bunda berbadan dua, kelahiran, kematian balita, kematian bunda berbadan dua, melahirkan, nifas, balita dan bayi yang terdapat di daerah posyandu, catatan pemberian vitamin A, pemberian oralit, tanggal dan status pemberian imunisasi, dan pencatatanpencatatan lingkup posyandu dan laporan aktivitas tiap bulannya. Umumnya dalam pendataan dan pencatatannya kader posyandu masih memakai kertas secara manual, perihal ini pasti tidak efektif sebab banyaknya informasi yang wajib dicatat tiap bulannya dan jumlah anak dan hasil pengecekan berbeda, dapat meningkat ataupun menurun, buat penyusunan laporan juga wajib di perbarui tiap terdapat aktivitas, dan belum lagi bila terdapat informasi yang salah. Bila memakai kertas terus menerus pastinya kurang ramah area dan juga tidak efisien bila buat memperbarui informasi. Dahulu hanya sebagian kecil orang dapat menggunakan pc tetapi saat ini bersamaan dengan pertumbuhan pc yang begitu kilat bisa menggunakan semaksimal 
mungkin. Saat ini pc tumbuh sangat pesat, nyaris tiap tahun pc senantiasa hadapi pertumbuhan. Dengan kemajuan pertumbuhan teknologi pc hingga proses pelayanan warga spesialnya posyandu bisa berlangsung efisien dan efektif. Buat itu diperlukan sebagian sarana pendukung, dimana salah satu sarana pendukung tersebut merupakan aplikasi yang bisa menolong mencerna informasi. Hingga dari itu sokongan media pc sangatlah diperlukan spesialnya di pelayanan warga yang kita tahu selaku Posyandu. Dengan terdapatnya aplikasi pendukung di posyandu ini hingga pengolahan informasi bunda, balita, dan anggota posyandu hendak berjalan efisien dan efektif. Mengingat informasi yang terdapat di posyandu bukan merupakan informasi yang terkomputerisasi melainkan dalam wujud kertas dan tabel, sehingga kerap terjalin kesalahan pencatatan informasi balita paling utama pada dikala perekapan informasi ke buku besar.

Tidak hanya itu juga tidak tidak sering pengurus posyandu kerap hadapi hambatan dalam mencari informasi balita disebabkan jumlah informasi yang tidak sedikit sehingga menyebabkan minimnya dalam pengontrolan terhadap balita sehingga pemberian vitamin dan imunisasi teratur tidak berjalan dengan baik yang menyebabkan tersendatnya pembuatan laporan bulanan dan lampiran tahunan. Dengan ini hingga diperlakukan aplikasi Sistem Pendataan Imunisasi di Posyandu Wijaya Kusuma. Aplikasi sistem pendataan imunisasi posyandu yang hendak terbuat ini, terbuat memakai bahasa pemrograman Java dan MySQL. Nantinya aplikasi ini hendak digunakan buat menolong kader posyandu bisa mencerna informasi bunda dan anak dan laporan mulai dari memasukan, memperbarui, menghapus dan menghitung berat sempurna balita dan bayi. Sehingga bisa mempermudah dan membuat kerja kader lebih efektif.

Menurut (Hutahaean, 2015) sistem adalah suatu jaringan kerja dari prosedur-prosedur yang saling berhubungan, berkumpul bersamasama untuk melakukan kegiatan atau untuk melakukan sasaran tertentu.

Sistem merupakan kumpulan elemen yang silih berhubungan dalam satu kesatuan buat melaksanakan sesuatu proses pencapaian sesuatu tujuan utama. (Sutarman, 2012)
Menurut (Rizky, 2011) perancangan merupakan suatu proses buat mendefinisikan suatu yang hendak dikerjakan dengan memakai metode yang bermacam- macam dan didalamnya mengaitkan deskripsi menimpa arsitektur dan perinci komponen dan juga keterbatasan yang hendak dirasakan dalam proses pengerjaannya

Menurut (Satzinger, Jackson dan Burd, 2012) perancangan sistem merupakan sekumpulan kegiatan yang menggambarkan secara rinci gimana sistem hendak berjalan. Perihal itu bertujuan buat menciptakan produk fitur lunak yang cocok dengan kebutuhan user. Menurut (Sutarman, 2012) Sistem merupakan kumpulan elemen yang silih berhubungan dan berhubungan pada satu integritas buat mengaplikasikan sesuatu proses buat pencapaian sesuatu tujuan yang utama. Menurut Mulyadi (2016 : 5) Sistem merupakan suatu langkah jaringan yang dibuat menurut struktur yang terpadu untuk melakukan tindakan pokok perusahaan. Menurut (Azhar Susanto, 2013) sistem adalah serangkaian komponen yang dikoordinasikan untuk mencapai tujuan.

Menurut (Anggraeni \& Irviani, 2017) menjelaskan bahwa informasi merupakan sekumpulan data ataupun kenyataan yang di organisasikan ataupun diolah dengan metode tertentu sehingga memiliki makna untuk penerima. Menurut Sutabri dalam (Trimahardhika \& Sutinah, 2017) Informasi merupakan suatu data yang telah diolah, diklasifikasikan dan diinterprestasikan serta digunakan untuk proses pengambilan keputusan.

Menurut data Dinkes Provinsi Jawa Tengah (2015), Angka Kematian Bayi (AKB) sebesar 10 per 1.000 kelahiran hidup sedangkan Angka Kematian Balita (AKABA) sebesar 11,64 per 1.000 kelahiran. Terjadi penurunan tetapi tidak signifikan dibandingkan AKB tahun 2014 yaitu 10,08 per 1.000 kelahiran hidup. Angka kematian balita (AKABA) sebanyak 8 anak, sedangkan jumlah kelahiran hidup sebanyak 9.861 anak. Menurut (Kemenkes, 2011), manfaat penyelenggaraan Posyandu ialah: 1) buat menunjang perbaikan sikap; 2) menunjang sikap hidup bersih dan sehat; 3) menghindari penyakit yang berbasis area dan penyakit yang bisa dicegah dengan imunisasi; 
4) menunjang pelayanan Keluarga Berencana;

5) menunjang pemberdayaan keluarga dan warga dalam penganekaragaman pangan melalui pemanfaatan pekarangan.

Pada penelitian ini digunakan 2 riset terdahulu yang sangat berguna sebagai referensi ilmiah adalah penelitian terdahulu pertama yang dilakukan oleh Bagus Imam Saputra, Abdul Mufti, M. Candra pada tahun 2021 dengan mengambil judul Rancangan Aplikasi Sistem Administrasi Posyandu pada RW 03 Sunter Agung. Kasus yang dibahas pada riset ini yaitu media yang digunakan masih media kertas ataupun manual, pembuatan aplikasi ini guna memudahkan dalam pendataan supaya lebih efisien dalam menginput data.

Penelitian kedua yang dilakukan oleh Dede Sutanto , Reza Avrizal , Risma Nurul Auliya pada tahun 2021 dengan mengambil judul Sistem Pengolahan Data Administrasi Pasien Pada Klinik Pratama Pelabuhan Cirebon. Kasus yang dibahas pada riset ini ialah petugas klinik kesusahan dalam melacak data pasien serta mencari data pasien yang terdaftar, sebab sistem yang ada tidak bisa mendata pasien secara sistematis. Tidak hanya itu, proses pembayaran masih secara global, sehingga tidak diketahui rincian dari pembayaran yang berlaku. Sistem yang ada pula tidak bisa mencetak laporan- laporan, semacam: bukti pembayaran ataupun rekam kedokteran pasien.

\section{METODE PENELITIAN}

Dalam melaksanakan riset ini peneliti memakai riset Prosedur Research and Development serta prosedur kualitatif serta deskriptif. Dalam membuat langkah- langkah pengembangan sistem, digunakan prosedur terstruktur dengan Paradigma Siklus Hidup Klasik

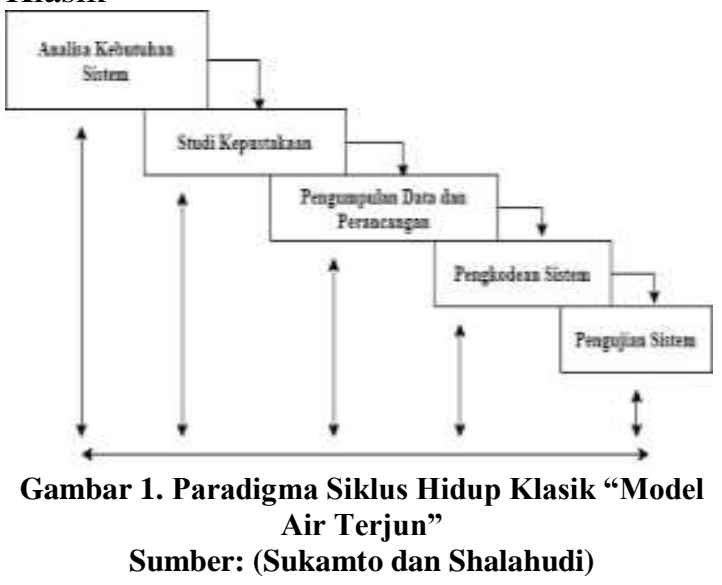

Prosedur pengumpulan data yang digunakan dalam penyusunan skripsi ini ialah Wawancara, Observasi, Dokumentasi serta Riset Literatur:

1. Wawancara: Wawancara dilakukan dengan metode tanya jawab secara lisan kepada narasumber yang berkompeten dibidangnya, semacam: Kepala Rw serta Kader Posyandu

2. Observasi: Pengamatan dilakukan dengan langsung terjun ke lapangan yang dilakukan dari Mei 2020 s. d. Juli 2021. Penulis melaksanakan peninjauan ke lapangan dengan mengamati penerapan sistem yang lagi berjalan serta mengamati jalannya informasi yang dianggap berarti.

3. Studi Literatur: Penelitian yang dicoba oleh pengamat dengan mengumpulkan beberapa buku buku, majalah yang berkaitan dengan permasalahan serta tujuan riset.

Langkah-langkah Pengembangan Sistem :

1. Analisis Kebutuhan Sistem: Ditahap menganalisa kebutuhan sistem dilakukan pengumpulan kebutuhan dengan berfokus pada perangkat lunak, meliputi: Informasi, fungsi masing-masing pada bagian sistem, kerja atau cara kerja, antar muka.

2. Studi Kepustakaan/ Studi Literatur: Kemudian didalam tahapan ini berfokus kepada pengumpulan data-data yang dibutuhkan dalam pengembangan sistem dengan cara membaca buku-buku ilmiah, mempelajari teori-teori yang berhubungan dengan pokok permasalahan yang akan dibahas dalam penulisan tugas akhir ini.

3. Pengumpulan Data dan Perancangan Sistem: Pada tahapan ini setelah semua data yang dibutuhkan sudah didapat maka dilakukan perancangan struktur data, arsitektur perangkat lunak, rincian karakteristik antar muka dilaksanakan pada tahapan ini.

4. Pengkodean Sistem: Pada tahapan ini dilakukan pengkodean sistem dari semua data yang telah di dapat ke dalam sebuah bahasa pemrograman dan di implementasikan ke dalam sebuah aplikasi dokumentasi pengajuan Asuransi agar lebih mudah digunakan dan dipahami.

5. Pengujian Sistem: Sebelum sistem aplikasi dokumentasi dapat digunakan dengan baik, harus dilakukan pengujian terlebih dahulu. Rangkaian pengujian ini dijalankan bersama-sama dengan data aktual dari 
sistem yang sudah ada atau sistem yang sedang berjalan.

\section{HASIL DAN PEMBAHASAN}

Aturan sistem pendataan imunisasi yang akan di usulkan pada Data Share Store adalah sebagai berikut:

1. Kader sebagai petugas akan login dan melakukan penginputan imunisasi

2. Petugas menginput data balita.

3. Petugas menginput data imunisasi.

4. Petugas menginput data vitamin

5. Petugas menginput hasil imunisasi dan vitamin

6. Petugas membuat laporan.

Berikut ini merupakan gambaran tentang sistem yang diusulkan pada system pendataan imunisasi pada Posyandu :

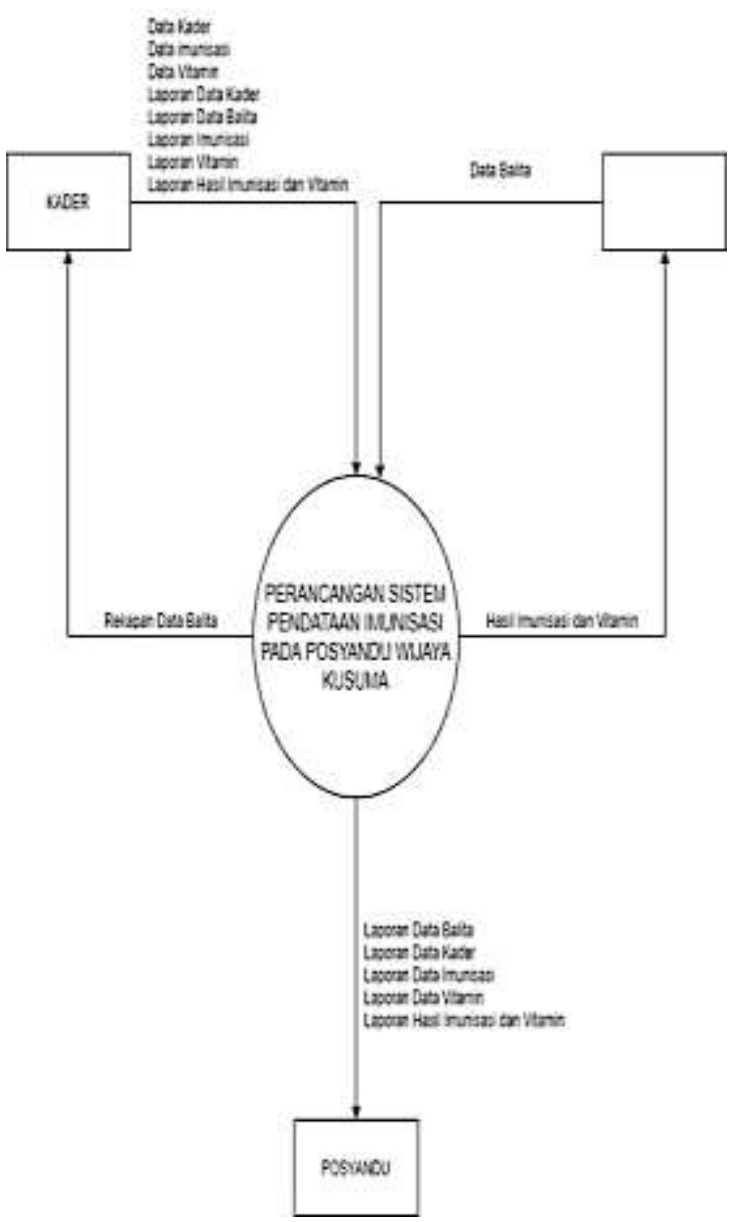

Gambar 2. Diagram Konteks

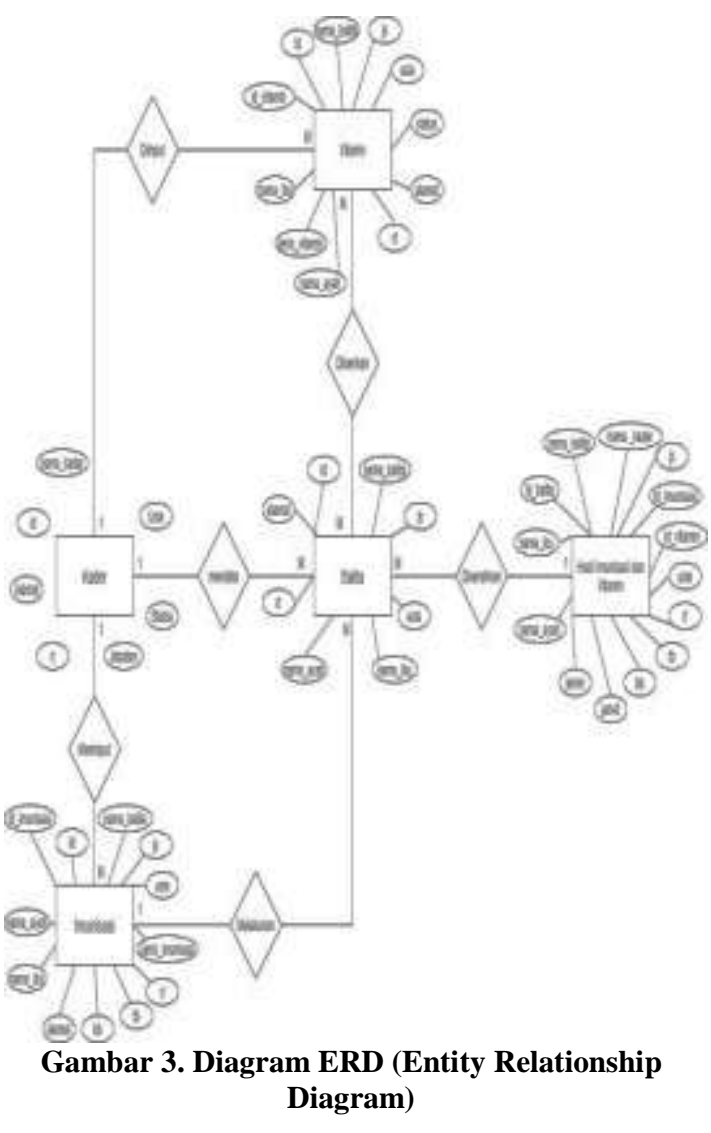

Selanjutnya penulis membuat aplikasi dengan menggunakan Java Netbeans berbasis desktop dan database mysql. Berikut ini adalah tampilan dari aplikasi perancangan sistem pendataan imunisasi pada posyandu wijaya kusuma :

\section{Tampilan Layar}

Rancangan Antar Muka atau Dialog Layar

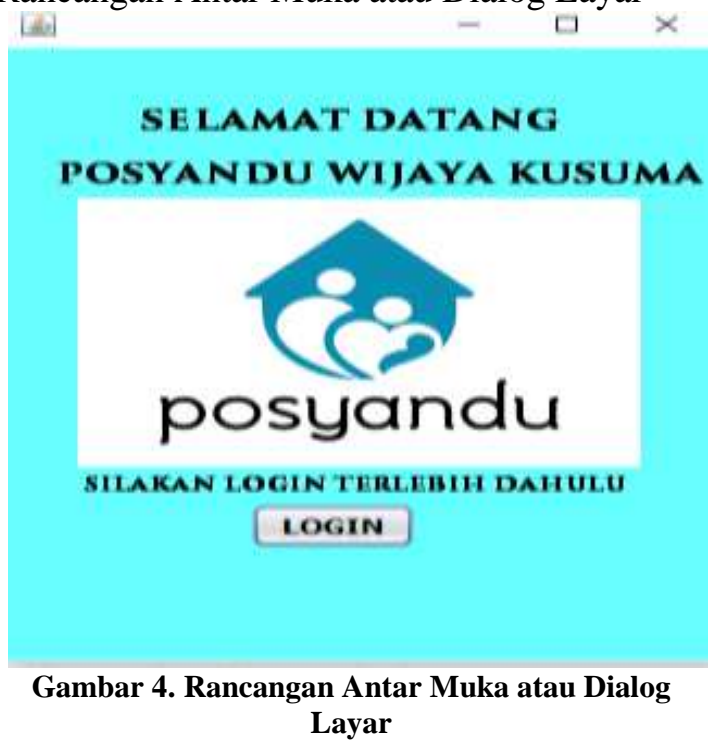

Pada tampilan ini pengguna hanya perlu klik "Login" 
Form Login

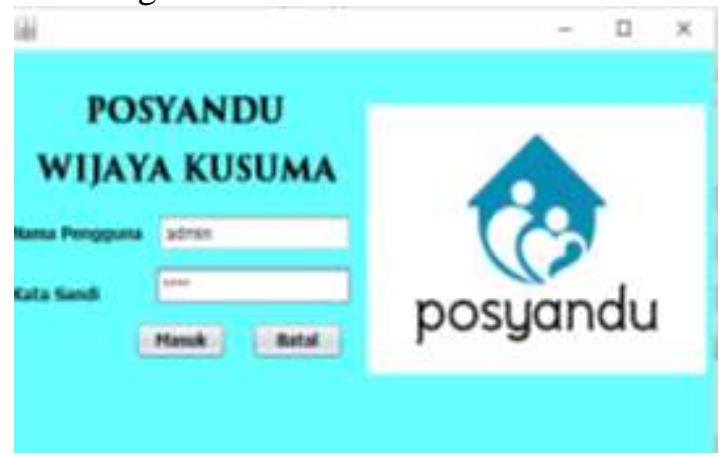

Gambar 5. Menu Login

Pada form ini digunakan sebagai kata kunci sebelum kita memasuki program utama, agar tidak sembarang orang dapat mengakses program ini. kader harus melakukan login terlebih dahulu agar dapat membuka menumenu yang ada didalam aplikasi tersebut.

Form Menu

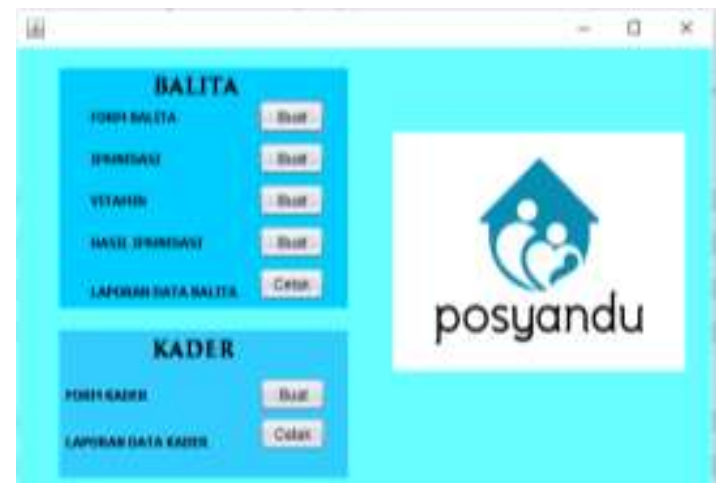

Gambar 6. Form Menu

Ini adalah tampilan menu utama, yang didalamnya terdapat menu-menu lain untuk memasukan atau mencetak data yang berkaitan dengan kegiatan Posyandu

Form data balita

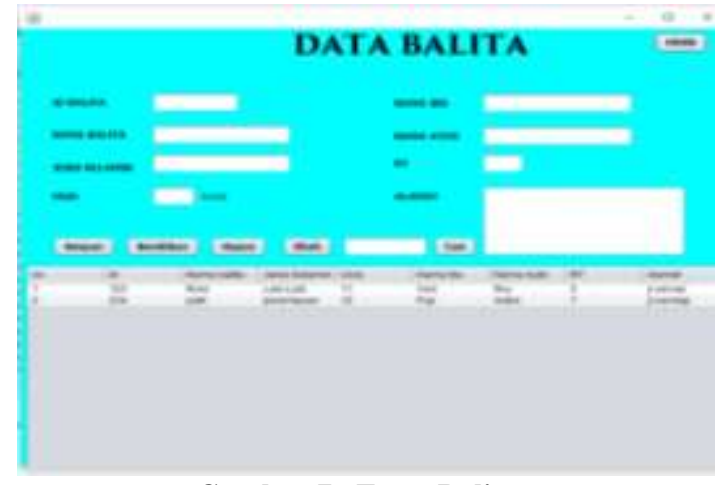

Gambar 7. Form Balita

Pada form ini adalah untuk penginputan data balita yang ingin melakukan imunisasi dan pemberian vitamin.
Form data Imunisasi

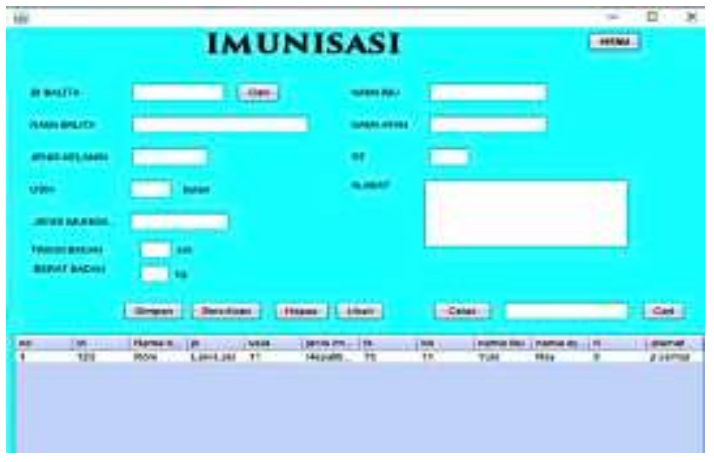

Gambar 8. Form Imunisasi

Pada form ini adalah untuk penginputan data untuk mengetahui jenis imunisasi apa yang di berikan kepada balita.

Form data vitamin

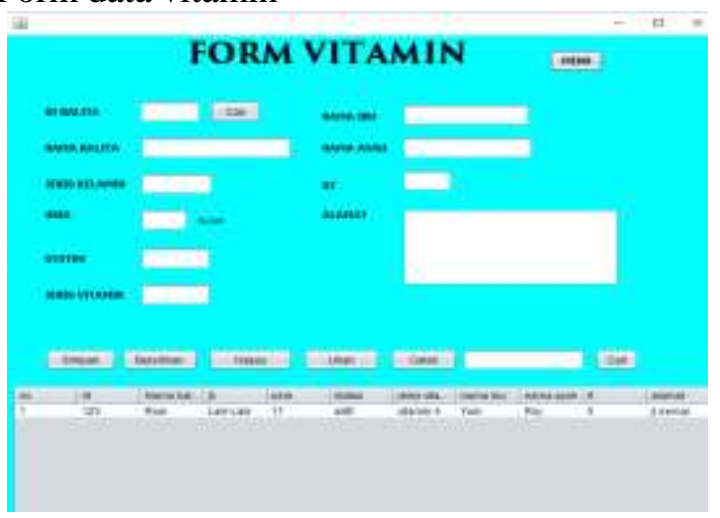

Gambar 9. Form Vitamin

Pada form ini adalah untuk penginputan data untuk mengetahui jenis vitamin apa yang diberikan kepada balita

Form Hasil Imunisasi dan Vitamin

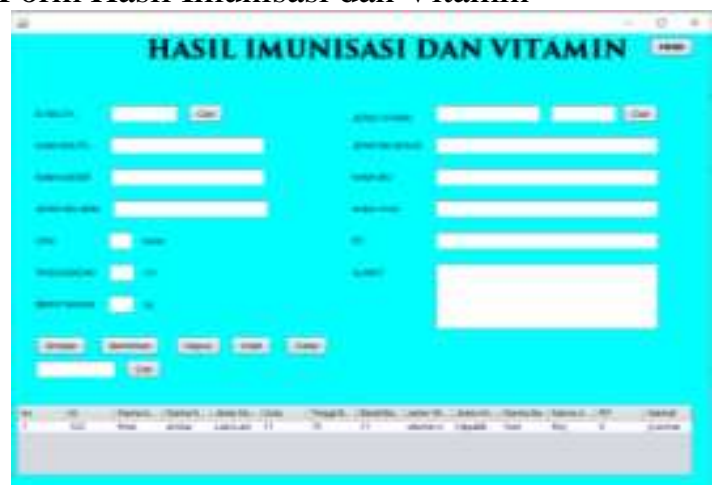

Gambar 10. Form Hasil Imunisasi dan Vitamin

Pada form ini adalah untuk penginputan data balita agar mengetahui secara lengkap jenis imunisasi dan jenis vitamin apa yang diberikan 


\section{Form Kader}

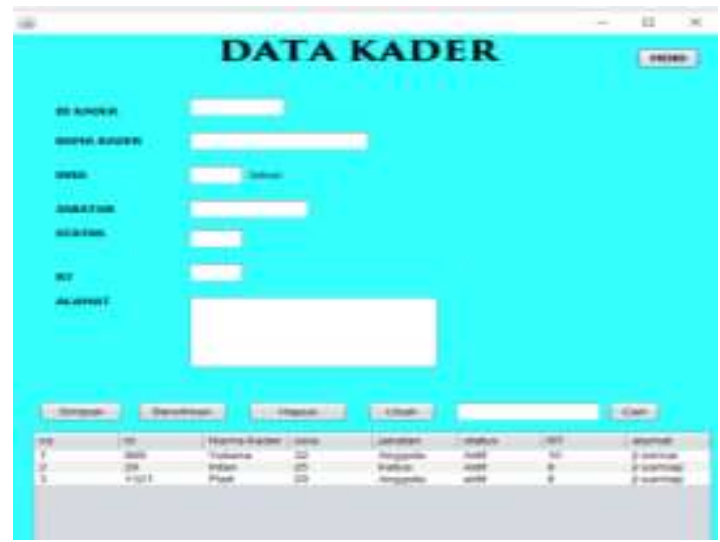

Gambar 11. Form Kader

Pada Form ini adalah untuk penginputan data kader yang nantinya akan menggunakan aplikasi tersebut serta untuk mengetahui kader yang bertugas

\section{Laporan Data Balita}

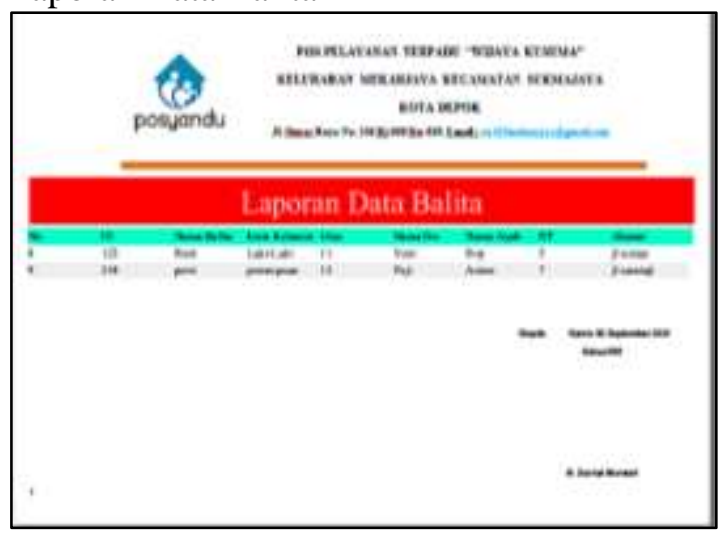

Gambar 12. Laporan Data Balita

Ini adalah laporan data balita setelah dicetak

Laporan Data Kader

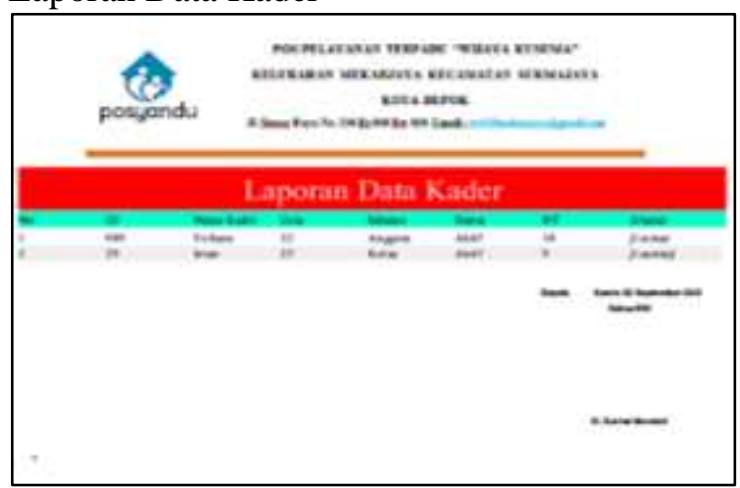

Gambar 13. Laporan Data Kader

Ini adalah laporan data kader setelah dicetak
Laporan Data Imunisasi

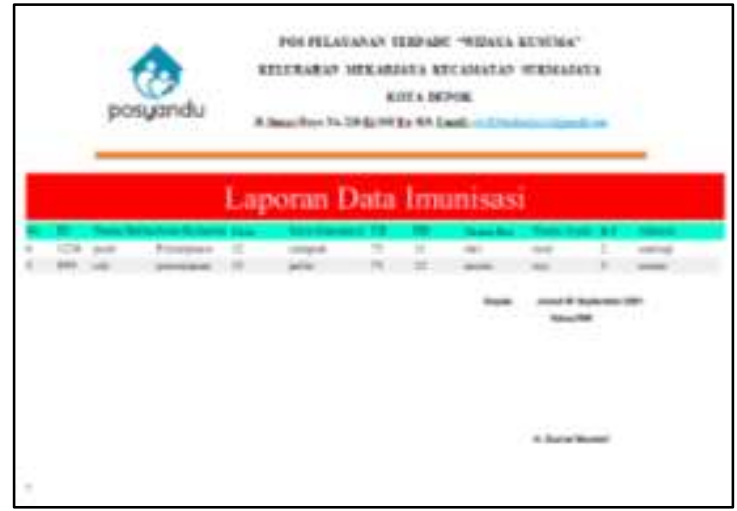

Gambar 14. Laporan Data Imunisasi

Ini adalah laporan data imunisasi balita setelah melakukan kegiatan posyandu.

Laporan Vitamin

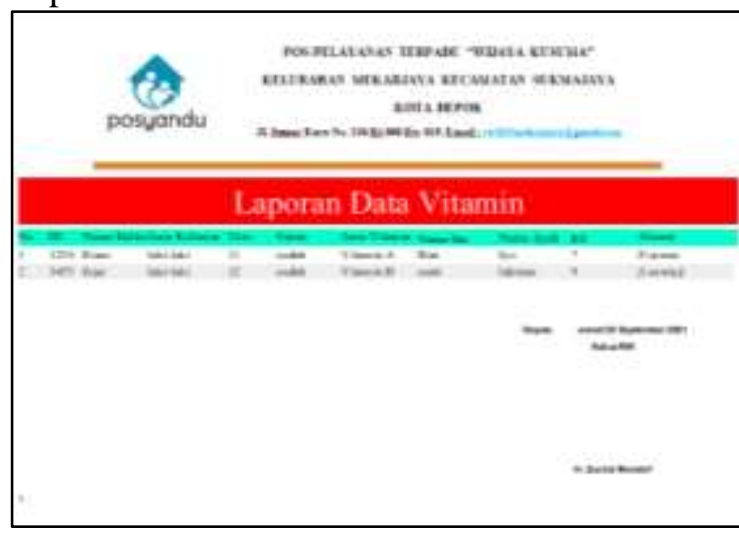

Gambar 15. Laporan Data Vitamin

Ini adalah laporan data vitamin setelah melakukan pemberian vitamin.

Laporan Hasil Imunisasi dan Vitamin

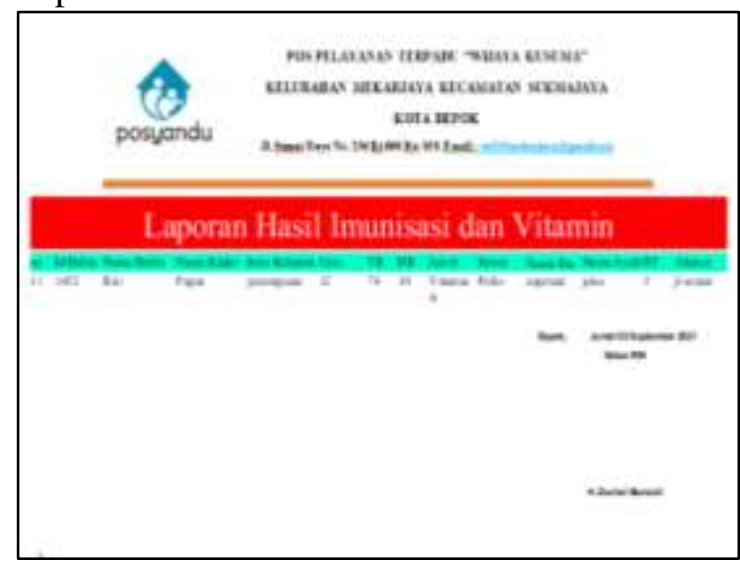

Gambar 16. Laporan Hasil Imunisasi dan Vitamin

Ini adalah laporan Hasil imunisasi dan vitamin setelah dicetak 


\section{SIMPULAN DAN SARAN}

Berdasarkan penelitian yang telah dilakukan, didapatkan beberapa kesimpulan, antara lain:

Sistem pencatatan dan pengolahan data pada Posyandu Wijaya Kusuma masih manual. Aplikasi sistem pencatatan data pada Posyandu Wijaya Kusuma dapat digunakan untuk mengolah data-data balita sehingga menjadi efektif dan efisien. Implementasi dari hasil Aplikasi sistem pencatatan dan pengolahan data pada posyandu kedalam menggunakan bahasa pemrograman Java menghasilkan program aplikasi berbasis database yang dapat menyimpan data balita, dan mencetak laporan secara akurat dan tepat waktu.

Berdasarkan penelitian yang telah dilakukan, maka saran yang dapat disampaikan adalah diharapkan kepada semua pihak pengelolaan posyandu untuk meningkatkan peran serta dalam memberikan dukungan terhadap kesuksesan program posyandu di masyarakat dan kepada semua masyarakat setempat diharapkan dapat meningkatan partisipasinya secara aktif dalam membantu pemerintah untuk melaksanakan program posyandu, sehingga dapat menjadikan masyarakat tersebut sehat dan terhindar dari segala bentuk penyakit yang berakibat pada kematian.

\section{DAFTAR PUSTAKA}

Anggraeni, E. Y. \& Irviani, R., 2017. Pengantar Sistem Informasi. Yogyakarta: Andi.

Azhar, Susanto. (2013). Sistem Informasi Akutansi. Bandung: Lingga Jaya.

Dinkes provinsi jawa tengah (2015). Pos Pelayanan Terpadu( Posyandu), 1-7.

Hutahean (2015). Journal of Chemical Information and Modeling Pengertian Sistem, 53(9), 287.

Sutarman (2012). Buku Pengantar Teknologi Informasi. Jakarta: Bumi Aksara.

Kemenkes (2011). Pos Pelayanan Terpadu( Posyandu), 4-17.

Mulyadi (2016). Sistem Informasi Akuntansi, Jakarta: Salemba Empat.

Rizky, S. (2011). Konsep Dasar Rekayasa Perangkat Lunak", Jakarta: Prestasi Pustaka.

Satzinger, J. W., Jackson, R. B., Burd, S. D. (2012). System Analysis and Design in A Changing World. USA: Cengage Learning.

Saputra, Bagus Imam, Mufti, Abdul \& Irawan, M. Chandra. (2021). Rancangan Aplikasi Sistem Administrasi Posyandu Pada Rw 03 Sunter Agung. Jurnal Riset dan Aplikasi Mahasiswa Informatika (JRAMI), Vol.2 No.3, 498-505. Retrieved from

http://jim.unindra.ac.id/index.php/jrami/ article/viewFile/1446/524.

Trimahardhika, R., \& Sutinah, E. (2017). Development Dalam Perancangan Sistem Informasi Perpustakaan. Jurnal Informatika, Vol.4 No.2(2), 250. Retrieved from http://ejournal.bsi.ac.id/ejurnal/index.ph p/ji/article/view/22269. 